\section{SUMMARY}

1. The polysaccharide produced by rumen strains of Streptococcus bovis from sucrose at $37^{\circ}$, in the presence of carbon dioxide, yielded only glucose on hydrolysis.

2. Isomaltose was isolated and identified as the sole disaccharide produced by partial acid hydrolysis of the polysaccharide, which is therefore a dextran.

3. On the evidence of periodate oxidation, infrared spectra and optical rotations it is concluded that the dextrans produced by six strains of $S$. bovis contain only $\alpha$-1:6-glucosidic linkages and are therefore unbranched.

4. Growth of one strain of $S$. bovis at a lower temperature $\left(28^{\circ}\right)$ or in a medium containing added magnesium still produced an unbranched dextran.

My thanks are due to Dr A. E. Oxford, of this Laboratory, who grew the additional cultures used in this work; and to Mr R. I. M. Fraser, of the Dominion Laboratory, Lower Hutt, who provided the infrared spectrograms. Freezedried strains of the organism were kindly provided by Dr P. N. Hobson of the Rowett Research Institute, Aberdeen, and the specimen of $\beta$-isomaltose octa-acetate by Dr S. A. Barker, Chemistry Department, Birmingham University. The technical assistance of Miss J. Michael is gratefully acknowledged.

\section{REFERENCES}

Bailey, R. W., Barker, S. A., Bourne, E. J. \& Stacey, M. (1957). J. chem. Soc. p. 3530.

Bailey, R. W. \& Oxford, A. E. (1958). J. gen. Microbiol. $19,130$.
Barker, S. A., Bourne, E. J., Bruce, G. T., Neely, W. B. \& Stacey, M. (1954a). J. chem. Soc. p. 2395.

Barker, S. A., Bourne, E. J., Stacey, M. \& Whiffen, D. H. (1954b). J. chem. Soc. p. 171.

Barker, S. A., Bourne, E. J., James, A. E., Neely, W. B. \& Stacey, M. (1955a). J. chem. Soc. p. 2096.

Barker, S. A., Pautard, F., Siddiqui, I. R. \& Stacey, M. (1955b). Chem. \& Ind. p. 1450.

Bayly, R. J. \& Bourne, E. J. (1953). Nature, Lond., 171, 385.

Dain, J. A., Neal, A. L. \& Seely, H. W. (1956). J. Bact. 72, 209.

Hehre, E. J. \& Neil, J. M. (1946). J. exp. Med. 83, 145.

Jeanes, A. R., Haynes, W. C., Wilham, C. A., Rankin, J. C., Melvin, E. A., Austin, M. J., Cluskey, J. E., Fisher, B. E., Tsuchiya, H. M. \& Rist, C. E. (1954). J. Amer. chem. Soc. 76, 5041.

Jeanes, A. R. \& Wilham, C. A. (1950). J. Amer. chem. Soc. $72,2655$.

Jermyn, M. A. \& Isherwood, F. A. (1949). Biochem. J. 44, 402.

Montgomery, E. M., Weakly, F. B. \& Hilbert, G. E. (1949). J. Amer. chem. Soc. 71, 1682.

Niven, C. F., Smiley, K. L. \& Sherman, J. M. (1941). $J$. biol. Chem. 140, 105.

Partridge, S. M. (1949). Nature, Lond., 164, 443.

Pirt, S. J. \& Whelan, W. J. (1951). J. Sci. Fd Agric. 2, 224.

Shaffer, P. A. \& Hartmann, A. F. (1921). J. biol. Chem. 124, 425.

Topley, W. W. C. \& Wilson, G. S. (1946). Principles of Bacteriology and Immunity, 3rd ed., p. 600. Ed. by Wilson, G. S. \& Miles, A. A. London: Edward Arnold and Co.

Trevelyan, W. E., Procter, D. P. \& Harrison, J. S. (1950). Nature, Lond., 166, 444.

Whistler, R. L. \& Durso, D. F. (1950). J. Amer. chem. Soc. $72,677$.

\title{
The Anaerobic Metabolism of Citrate in Rat Liver
}

\author{
BY W. BARTLEY, M. SOBRINHO-SIMÕES,* BRENDA M. NOTTON AND GRAZIA MONTESI $\dagger$ \\ Cell Metabolism Research Unit, Department of Biochemistry, University of Oxford
}

(Received 10 June 1958)

In experiments with washed particles of rat liver, Vignais, Vignais \& Bartley (1957) showed that under aerobic conditions the uptake of oxygen was insufficient to account for the removal of tricarboxylic acids. This paper is concerned with the examination of the products of anaerobic citrate metabolism in washed particulate preparations of rat liver.

* Present address: Faculdade de Medicina, Universidade de Porto, Porto, Portugal.

† Present address: Biochemistry Dept., Vanderbilt University Medical School, Nashville, Tenn.

\section{EXPERIMENTAL}

Washed particles. Rats were stunned and beheaded and the livers were rapidly removed and chilled in ice. After removal of surplus ice the livers were minced in the Fischer mincer (Jouan, Paris). The pulp from one liver (8-10 g.) was homogenized with $30 \mathrm{ml}$. of $0.9 \% \mathrm{KCl}$ soln. in a stainless-steel homogenizer of the Potter-Elvehjem type. The homogenate was made to $60 \mathrm{ml}$. with $0.9 \% \mathrm{KCl}$ soln., and the particulate material that sedimented after centrifuging at $0^{\circ}$ for $15 \mathrm{~min}$. at $2000 \mathrm{~g}$ was collected and washed twice on the centrifuge with $30 \mathrm{ml}$. of $0.9 \% \mathrm{KCl}$, the same centrifugal conditions being used for both washings. 
This mixture of washed nuclei and mitochondria is similar to that used by Green, Loomis \& Auerbach (1948) and named by them 'cyclophorase'. Because it is very quickly and easily prepared 'cyclophorase' was used for all the experiments illustrated in this paper, but other unpublished work indicates that mitochondrial preparations isolated from $0.25 \mathrm{M}$-sucrose according to Werkheiser \& Bartley (1957) consumed citrate at about the same rate as the 'cyclophorase' preparations.

Special chemicals. ${ }^{14} \mathrm{C}$-Labelled citrate was a gift from Dr H. L. Kornberg. It had been prepared by incubation of ${ }^{14} \mathrm{C}$-labelled acetate with oxaloacetate in the presence of a bacterial extract which contained condensing enzyme. The products of the reaction were separated on a paper chromatogram with the solvents of Kornberg (1958) and the citrate area was eluted with water. It is not completely certain that the ${ }^{14} \mathrm{C}$-labelled citrate was entirely free from other compounds. Diphosphopyridine nucleotide (DPN), triphosphopyridine nucleotide (TPN) and adenosine triphosphate (ATP) were obtained from Sigma Chemical Co., St Louis, Mo., U.S.A.; other chemicals were commercial products, of A.R. standard when available.

Incubation procedure. To the main compartment of each Warburg vessel standing in cracked ice was added $2 \mathrm{ml}$. of particles (usually about $100 \mathrm{mg}$. dry wt.) suspended in $0.9 \% \mathrm{KCl}$ and the other additions which are described in the individual experiments. The citrate was added to the side arm and the centre well contained a stick of yellow phosphorus. The final fluid volume was $4 \mathrm{ml}$. When the vessels were attached to the manometers they were placed in a rack so that the vessels were immersed in an ice-water bath. Each vessel was gassed for at least 5 min. with $\mathrm{O}_{2}$ free $\mathrm{N}_{2}$ and then left to stand in the ice-water bath for 15 min. with the taps closed. During this time the vessels were gently shaken to ensure thorough anaerobiosis. The contents of the side arm were then mixed and the manometers were shaken in a water bath at $40^{\circ}$. The manometers were removed from the bath at various times and the reaction was stopped by the addition of $0.5 \mathrm{ml}$. of $30 \%$ trichloroacetic acid to the vessel. After removal of the precipitated protein by centrifuging the supernatant fluid was stored at $-18^{\circ}$ until it could be analysed.

Enzyme preparations. Fumarase (Massey, 1952) was purified to the stage of the first $\left(\mathrm{NH}_{4}\right)_{2} \mathrm{SO}_{4}$ fractionation. Aconitase was either the crude preparation of Krebs \& Eggleston (1944) or later the purified preparation of Morrison (1954) taken as far as the first $\left(\mathrm{NH}_{4}\right)_{2} \mathrm{SO}_{4}$ fractionation stage. Succinoxidase was prepared from pigeon-breast muscle as described by Krebs (1937). TPN isocitric dehydrogenase was prepared according to Ochoa (1948).
Chemical estimations. Succinate was measured by an unpublished method of Bartley \& Notton involving conversion into malate with succinoxidase and subsequent fluorimetric estimation of the malate (Hummel, 1949). $\beta$-Hydroxybutyrate was estimated by the method of Greenberg \& Lester (1944) as modified by R. G. Kulka (unpublished work). Malate was estimated either with Lactobacillus arabinosus by the method of Nossal (1951) or fluorimetrically as described by Hummel (1949). Carbohydrate was hydrolysed to glucose and estimated according to Miller \& Van Slyke (1936). Other chemical estimations were by the following methods: citrate, Taylor (1953); $\alpha$ keto acids, Friedemann \& Haugen (1943); total amino acids, Rosen (1957); acetate, Serlin \& Cotzias (1955); lactate, Barker \& Summerson (1941).

Tissue dry weights. A measured volume of the tissue suspension was dried at $105^{\circ}$ for $24 \mathrm{hr}$. and weighed. In calculation of tissue activities no correction was made for the $\mathrm{KCl}$ content of the suspensions.

Paper chromatography. 2:4-Dinitrophenylhydrazones of $\alpha$-keto acids were separated according to El Hawary \& Thompson (1953); organic acids by two-dimensional chromatography according to Kornberg's (1958) modifications of the method of Calvin \& Benson (1949). Radioautographs were made as described by Kornberg (1958) and the radioactivity was counted on the chromatograms with a large end-window counter $(5 \mathrm{~cm}$. diameter).

Reproducibility. Normally the data were derived from chemical analysis of the contents of a single Warburg vessel and from measurements of gas changes made in the vessel during incubation. Sufficient preliminary work was done to show that the gas output in duplicate vessels incubated for the same time and under the same conditions was the same. In the chemical determination of tricarboxylic acid duplicate determinations were made. These always agreed by better than $5 \%$.

\section{RESULTS}

Comparison of the aerobic and anaerobic metabolism of tricarboxylic acids by rat-liver particles. Table 1 shows the comparative consumption of citrate by washed particles of rat liver under anaerobic or aerobic conditions. The anaerobic consumption of tricarboxylic acid is approximately one-half of that consumed aerobically. The $Q_{\mathrm{O}_{2}}$ of the preparation was 35 ( $\mu \mathrm{l}$. of $\mathrm{O}_{2} / \mathrm{mg}$. dry wt./hr.). Thus the ratio, $\mathrm{O}_{2}$ consumption/tricarboxylic acid consumption $(1 \cdot 5 / 0 \cdot 88)$, indicates that the citrate consumed

\section{Table 1. Comparison of the aerobic and anaerobic metabolism of citric acid by rat-liver particles}

Warburg vessels contained $131 \mathrm{mg}$. dry wt. of particles added in $2.5 \mathrm{ml}$. of $0.9 \% \mathrm{KCl}$ soln., $0.2 \mathrm{ml}$. of $5 \mathrm{mM}-\mathrm{ATP}$, $0.2 \mathrm{ml}$. of $5 \mathrm{mM}-\mathrm{MgCl}_{2}, 0.2 \mathrm{ml}$. of $0.1 \mathrm{M}$-potassium phosphate buffer, pH 7.4, and $1.4 \mathrm{ml}$. of $0.9 \% \mathrm{KCl} ; 0.1 \mathrm{ml}$. of $0.5 \mathrm{M}$ citrate was added from the side arm. The reaction was stopped by the addition of $0.5 \mathrm{ml}$. of $30 \%$ trichloroacetic acid. Samples of the extracts were analysed for citric acid after the action of aconitase.

\begin{tabular}{|c|c|c|c|c|}
\hline \multirow{2}{*}{$\begin{array}{l}\text { Incubation } \\
\text { time } \\
\text { (min.) }\end{array}$} & \multicolumn{2}{|c|}{$\begin{array}{c}\text { Total tricarboxylic acid } \\
\text { content of vessels } \\
\text { ( } \mu \text { moles })\end{array}$} & \multicolumn{2}{|c|}{$\begin{array}{l}\text { Tricarboxylic acid consumptior } \\
(\mu \mathrm{mole} / \mathrm{mg} . \text { dry wt./hr. })\end{array}$} \\
\hline & Anaerobic & Aerobic & In $\mathrm{N}_{2}$ & In $\mathrm{O}_{2}$ \\
\hline $\begin{array}{r}0 \\
30\end{array}$ & $\begin{array}{l}72 \\
43 \cdot 9\end{array}$ & $\begin{array}{l}72 \\
11 \cdot 7\end{array}$ & $\overline{0.38}$ & $\overline{0.88}$ \\
\hline
\end{tabular}


was not being completely oxidized, but that the oxidation proceeded past the stage of $\alpha$-oxoglutarate (see Vignais et al. 1957).

Effect of the tissue concentration on anaerobic formation of carbon dioxide from citrate and citrate removal. Although more tricarboxylic acid was consumed when the amount of tissue was increased the amount reacting was not proportional to the amount of tissue. The ratio of $\mathrm{CO}_{2}$ production to tricarboxylic acid consumed was greater with higher concentrations of tissue (Table 2), and reached values above $1 \cdot 0$. Two reactions may be expected to occur (Stern, Shapiro, Stadtman \& Ochoa, 1951) whereby citrate is metabolized:

$$
\begin{aligned}
& \text { Citrate + coenzyme } \mathrm{A} \rightarrow \begin{array}{c}
\text { oxaloacetate }+ \\
\text { acetyl coenzyme A }
\end{array} \\
& \text { Citrate } \rightarrow \text { isocitrate } \rightarrow \alpha \text {-oxoglutarate }+\mathrm{CO}_{2}+2 \mathrm{H} .
\end{aligned}
$$

Reaction (2) is dependent on a supply of TPN and DPN and on an acceptor for the hydrogens removed from the isocitrate. On the other hand, the

Table 2. Effect of the amount of tissue on the anaerobic citrate consumption and carbon dioxide production by washed particles of rat liver

Warburg vessels contained $0.5 \mathrm{ml}$. of $0.1 \mathrm{M}-2$-amino-2hydroxymethylpropane-1:3-diol (tris) buffer, $\mathrm{pH} 7 \cdot 4$, and washed particles of rat liver (amounts indicated) suspended in $0.9 \% \mathrm{KCl}$. The side arm contained $0.1 \mathrm{ml}$. of $0.5 \mathrm{M}-$ sodium citrate. The final volume in each flask was made to $4 \mathrm{ml}$. with $0.9 \% \mathrm{KCl}$. Gas phase was $\mathrm{N}_{2}$, the incubation temperature $40^{\circ}$ and the incubation time $2 \mathrm{hr}$. The reaction was stopped by the addition of $0.5 \mathrm{ml}$. of $30 \%(w / v)$ trichloroacetic acid.

\begin{tabular}{cccc}
$\begin{array}{c}\text { Dry wt. } \\
\text { of tissue } \\
\text { (mg.) }\end{array}$ & $\begin{array}{c}\text { Output } \\
\text { of } \mathrm{CO}_{2} \\
(\mu \mathrm{moles})\end{array}$ & $\begin{array}{c}\text { Consumption } \\
\text { of tricarb- } \\
\text { oxylic acid } \\
(\mu \mathrm{moles})\end{array}$ & $\begin{array}{c}\text { Ratio, } \mathrm{CO}_{2} \\
\text { produced/ } \\
\text { tricarboxylic } \\
\text { acid consumed }\end{array}$ \\
$31 \cdot 6$ & 1.9 & $7 \cdot 0$ & 0.27 \\
63.4 & $6 \cdot 0$ & $8 \cdot 7$ & $0 \cdot 69$ \\
$126 \cdot 8$ & $10 \cdot 3$ & $14 \cdot 0$ & 0.74 \\
$253 \cdot 6$ & 24.4 & 22.7 & 1.07 \\
\hline
\end{tabular}

Table 3. Effect of the amount of citrate on the anaerobic citrate consumption and carbon dioxide production by washed particles of rat liver

Warburg vessels contained $2 \mathrm{ml}$. of washed particles of rat liver (152 mg. dry wt.) suspended in $0.9 \% \mathrm{KCl}$ and $0.5 \mathrm{ml}$. of $0.1 \mathrm{M}$-tris buffer, $\mathrm{pH} 7.4 ; 0.1 \mathrm{M}$-sodium citrate was added from the side arms in the volumes shown below. Other details are as described in Table 2.

$\begin{array}{cccc}\begin{array}{c}\text { Vol. of } \\ \text { citrate } \\ (\mathrm{ml})\end{array} & \begin{array}{c}\text { Output } \\ \text { of } \mathrm{CO}_{2} \\ (\mu \text { moles })\end{array} & \begin{array}{c}\text { Consumption } \\ \text { of tricarb- } \\ \text { oxylic acid } \\ (\mu \text { moles })\end{array} & \begin{array}{c}\text { Ratio, } \mathrm{CO}_{2} \\ \text { produced/ } \\ \text { tricarboxylic } \\ \text { acid consumed }\end{array} \\ 0 & 0 \cdot 62 & - & - \\ 0 \cdot 05 & 6.90 & 4 \cdot 29 & 1 \cdot 61 \\ 0 \cdot 10 & 7 \cdot 15 & 4 \cdot 65 & 1 \cdot 54 \\ 0 \cdot 20 & 12 \cdot 58 & 8 \cdot 60 & 1 \cdot 46 \\ 0.50 & 16.30 & 14.90 & 1 \cdot 09\end{array}$

dissimilation reaction (1) can occur without these coenzymes. It is possible that the increase of tissue increases the ratio $\mathrm{CO}_{2}$ produced/tricarboxylic acid consumed by contributing a greater amount of endogenous cofactors.

Effect of citrate concentration. As shown in Table 3 an increase of citrate concentration resulted in a lowering in the ratio $\mathrm{CO}_{2}$ production/tricarboxylic acid consumption.

Effect of di-and tri-phosphopyridine nucleotide and adenosine triphosphate on citrate consumption and carbon dioxide production. Table 4 shows the effect of DPN, TPN and ATP on the anaerobic citrate consumption and on $\mathrm{CO}_{2}$ production. When added separately both DPN and TPN stimulated the removal of citrate to the same extent (Table 4), but TPN stimulated $\mathrm{CO}_{2}$ production more than DPN. ATP alone gave a small increase in consumption of tricarboxylic acid but a large increase in $\mathrm{CO}_{2}$ production. When TPN and ATP were added together the increase in $\mathrm{CO}_{2}$ and tricarboxylic acid removal were larger than with TPN alone and there was an increase in the ratio $\mathrm{CO}_{2}$ production/ citrate consumption. When DPN and ATP were added together an increase in citrate consumption and $\mathrm{CO}_{2}$ production occurred but the ratio $\mathrm{CO}_{2}$ produced/citrate consumed did not change.

Effect of magnesium. When magnesium (mM) was added alone there was a diminution in the tricarboxylic acid removed without alteration in the $\mathrm{CO}_{2}$ production (Table 4). In the presence of DPN or TPN (Table 4), with or without ATP, magnesium had various effects; thus when added with DPN it slightly increased the removal of tricarboxylic acid and increased the $\mathrm{CO}_{2}$ production, but when ATP was also present the consumption of tricarboxylic acid was reduced and the $\mathrm{CO}_{2}$ production was unaltered. In the presence of TPN magnesium did not alter the consumption of tricarboxylic acid but reduced $\mathrm{CO}_{2}$ production. When ATP was present, together with the TPN, there was virtually no effect of magnesium.

Effect of dithionite, hydroxylamine and ethylenediaminetetra-acetic acid. Dithionite might be expected to inhibit any reactions involving dehydrogenations, as it would reduce all the possible hydrogen acceptors. As shown in Table 5, this in fact did occur, as the addition of dithionite caused a marked diminution in the tricarboxylic acid consumed and an even greater drop in the $\mathrm{CO}_{2}$ evolved. The addition of hydroxylamine had only a slight effect in reducing consumption of tricarboxylic acid but did reduce the $\mathrm{CO}_{2}$ production by about $30 \%$. It was unexpected that the addition of ethylenediaminetetra-acetic acid (EDTA) should also reduce the consumption of tricarboxylic acid. This effect of EDTA was not seen when the incubation medium contained magnesium chloride. 
Effect of cyanide on the consumption of tricarb. oxylic acid. The addition of cyanide (0.01 M) completely inhibited the disappearance of citrate.

Effect of phosphate on the consumption of tricarboxylic acid. Substituting phosphate buffer for 2amino-2-hydroxymethylpropane-1:3-diol (tris) had no effect on the disappearance of tricarboxylic acid.

Products of the anaerobic metabolism of citrate. Malate and $\alpha$-oxoglutarate accumulated on incubation of citrate with liver (Table 6). These two substances probably arise by the oxaloacetate

Table 4. Effect of magnesium, adenosine triphosphate, diphosphopyridine nucleotide and triphosphopyridine nucleotide on the anaerobic citrate consumption and carbon dioxide production of washed particles of rat liver

Incubation conditions were as described in Table 3. Dry wt. of tissue/vessel in Expts. 1 and $2=79 \cdot 2$ mg., and in Expt. 3=111.6 mg.

\begin{tabular}{|c|c|c|c|c|c|}
\hline $\begin{array}{c}\text { Expt. } \\
\text { no. }\end{array}$ & Addition & $\begin{array}{l}\text { Amount of } \\
\text { addition } \\
\text { ( } \mu \text { moles) }\end{array}$ & $\begin{array}{c}\text { Output } \\
\text { of } \mathrm{CO}_{2} \\
(\mu \text { moles })\end{array}$ & $\begin{array}{l}\text { Consumption of } \\
\text { tricarboxylic acid } \\
(\mu \text { moles })\end{array}$ & $\begin{array}{c}\text { Ratio, } \mathrm{CO}_{2} \\
\text { produced/ } \\
\text { tricarboxylic } \\
\text { acid consumed }\end{array}$ \\
\hline \multirow[t]{5}{*}{1} & None & - & 8.0 & $12 \cdot 3$ & 0.65 \\
\hline & TPN & $1 \cdot 3$ & $13 \cdot 5$ & $13 \cdot 9$ & 0.97 \\
\hline & $\begin{array}{l}\mathrm{TPN}+ \\
\mathrm{MgCl}_{2}\end{array}$ & $\left.\begin{array}{l}1 \cdot 3 \\
4 \cdot 0\end{array}\right\}$ & $9 \cdot 8$ & $13 \cdot 9$ & 0.71 \\
\hline & $\begin{array}{l}\text { TPN + } \\
\text { ATP }\end{array}$ & $\left.\begin{array}{l}1 \cdot 3 \\
4 \cdot 0\end{array}\right\}$ & $15 \cdot 0$ & $16 \cdot 3$ & 0.92 \\
\hline & $\begin{array}{l}\mathrm{TPN}+ \\
\mathrm{MgCl}_{2}+ \\
\mathrm{ATP}\end{array}$ & $\left.\begin{array}{l}1 \cdot 3 \\
4 \cdot 0 \\
4 \cdot 0\end{array}\right\}$ & $15 \cdot 5$ & $15 \cdot 7$ & 0.99 \\
\hline \multirow[t]{2}{*}{2} & None & - & $10 \cdot 6$ & $10 \cdot 1$ & 1.05 \\
\hline & ATP & $4 \cdot 0$ & $17 \cdot 8$ & $12 \cdot 3$ & $1 \cdot 45$ \\
\hline \multirow[t]{6}{*}{3} & None & None & $13 \cdot 6$ & $12 \cdot 0$ & $1 \cdot 13$ \\
\hline & $\mathrm{MgCl}_{2}$ & $4 \cdot 0$ & $13 \cdot 7$ & $7 \cdot 2$ & 1.90 \\
\hline & DPN & 1.5 & $17 \cdot 5$ & $13 \cdot 9$ & $1 \cdot 26$ \\
\hline & $\begin{array}{l}\mathrm{DPCl}_{2} \\
\mathrm{DPN}^{2}\end{array}$ & $\left.\begin{array}{l}4.0 \\
1.5\end{array}\right\}$ & $15 \cdot 3$ & $14 \cdot 8$ & $1 \cdot 03$ \\
\hline & $\begin{array}{l}\text { DPN + } \\
\text { ATP }\end{array}$ & $\left.\begin{array}{l}1 \cdot 5 \\
4 \cdot 0\end{array}\right\}$ & $21 \cdot 0$ & $18 \cdot 3$ & $1 \cdot 15$ \\
\hline & $\begin{array}{l}\mathrm{MgCl}_{2}+ \\
\text { DPN }+ \\
\text { ATP }\end{array}$ & $\left.\begin{array}{l}4 \cdot 0 \\
1 \cdot 5 \\
4 \cdot 0\end{array}\right\}$ & $21 \cdot 4$ & $16 \cdot 5$ & $1 \cdot 29$ \\
\hline
\end{tabular}

Table 5. Effect of dithionite, hydroxylamine and ethylenediaminetetra-acetic acid on the anaerobic citrate consumption and carbon dioxide production of washed particles of rat liver

Incubation conditions were as described in Table 2. Dry wt. of tissue, $\mathbf{9 6 \cdot 2} \mathrm{mg}$./vessel.

\begin{tabular}{|c|c|c|c|c|}
\hline Addition & $\begin{array}{l}\text { Amount of } \\
\text { addition } \\
\text { ( } \mu \text { moles) }\end{array}$ & $\begin{array}{c}\text { Output } \\
\text { of CO } \\
(\mu \text { moles })\end{array}$ & $\begin{array}{l}\text { Consumption of } \\
\text { tricarboxylic acid } \\
(\mu \text { moles })\end{array}$ & $\begin{array}{c}\text { Ratio, } \mathrm{CO}_{2} \\
\text { produced } / \\
\text { tricarboxylic }\end{array}$ \\
\hline None . & - & $10 \cdot 5$ & $10 \cdot 1$ & $1 \cdot 04$ \\
\hline Dithionite & 30 & $4 \cdot 0$ & $6 \cdot 6$ & $0 \cdot 61$ \\
\hline Hydroxylamine & 40 & $7 \cdot 0$ & $\mathbf{9} \cdot \mathbf{1}$ & $0 \cdot 77$ \\
\hline Ethylenediaminetetra-acetic acid & 20 & $8 \cdot 0$ & $6 \cdot 6$ & $1 \cdot 23$ \\
\hline
\end{tabular}

Table 6. Formation of malate plus fumarate and $\alpha$-oxoglutarate during the anaerobic metabolism of citrate

Incubation conditions were as described in Table 2 except that in Expt. 3 incubation was for $1 \mathrm{hr}$. Expt. 2 is the same washed particle preparation as in Expt. 3 but it was incubated for the full time of $2 \mathrm{hr}$.

\begin{tabular}{|c|c|c|c|c|}
\hline $\begin{array}{c}\text { Expt. } \\
\text { no. }\end{array}$ & $\begin{array}{c}\text { Consumption of } \\
\text { tricarboxylic } \\
\text { acid } \\
\text { ( } \mu \text { moles })\end{array}$ & $\begin{array}{c}\text { Formation of } \\
\text { malate }+ \\
\text { fumarate } \\
\text { ( } \mu \text { moles })\end{array}$ & $\begin{array}{c}\text { Formation of } \\
\alpha \text {-oxoglutarate } \\
\text { ( } \mu \text { moles })\end{array}$ & $\begin{array}{c}\text { Percentage of } \\
\text { citrate recovered } \\
\text { as malate }+ \\
\text { fumarate }+ \\
\alpha \text {-oxoglutarate }\end{array}$ \\
\hline $\begin{array}{l}1 \\
2 \\
3 \\
4\end{array}$ & $\begin{array}{r}7 \cdot 6 \\
14 \cdot 2 \\
7 \cdot 6 \\
9 \cdot 4\end{array}$ & $\begin{array}{l}1 \cdot 2 \\
2 \cdot 1 \\
1 \cdot 4 \\
1 \cdot 9\end{array}$ & $\begin{array}{l}0 \cdot 34 \\
0 \cdot 55 \\
1 \cdot 30 \\
0 \cdot 30\end{array}$ & $\begin{array}{l}20 \\
18 \\
36 \\
23\end{array}$ \\
\hline
\end{tabular}


formed by (1) acting as hydrogen acceptor when isocitrate is dehydrogenated by (2). Not more than $36 \%$ of the citrate disappearing was accounted for in these two compounds and the amount of $\alpha$ oxoglutarate found was always less than the sum of malate and fumarate. Thus it appears that either citrate is metabolized by a pathway other than that of the citric acid cycle or the malate and $\alpha$ oxoglutarate are further metabolized. One conceivable pathway that has not yet been demonstrated in mammalian tissue is the cleavage of isocitrate to give glyoxalate and succinate (isocitritase: see Saz \& Hillary, 1956). However, no glyoxalate was ever detected as a product of the reaction as tested for by the addition of 2:4-di nitrophenylhydrazine and chromatography of the hydrazones on paper (see also Madsen, 1958). Further, no radioactivity appeared in glyoxalate when radioactive citrate was incubated anaerobically in the presence of glyoxalate. This possibility was not therefore pursued but tests were made for the products of the further metabolism of $\alpha$-oxoglutarate and malate.

Formation of glutamic acid. $\alpha$-Oxoglutarate in the presence of ammonium salts is rapidly reduced to glutamate by liver (Krebs, Eggleston \& Hems, 1948). Preliminary tests showed that the incubation of rat-liver particles with citrate under anaerobic conditions was accompanied by the appearance of a ninhydrin-reactive substance which ran on the paper chromatogram in the same position as glutamic acid. However, glutamic acid was also produced on the incubation of liver without added citrate. Thus the incubation of $150 \mathrm{mg}$. dry weight of particles with $56 \mu$ moles of citrate anaerobically for $2 \mathrm{hr}$. resulted in the formation of $12 \cdot 7 \mu$ moles of glutamate. Without citrate $3 \cdot 6 \mu$ moles of glutamate were formed. In another experiment radioactive citrate was incubated with rat liver anaerobically and the products of the reaction were isolated on the paper chromatograms and tested for radioactivity. About $30 \%$ of the counts that were lost from the citrate appeared in the glutamate spot. However, it is still not certain that all the excess of glutamate formed in the presence of the relatively high citrate concentrations was derived from the citrate. The amount of glutamate formed in the absence of citrate was variable, sometimes amounting to as much as $8-10 \mu$ moles $/ 150 \mathrm{mg}$. dry weight of tissue $/ 2 \mathrm{hr}$. When there was a high endogenous formation of glutamate the addition of citrate produced a comparatively small increase in the glutamate which accumulated. Paper chromatograms did not show a generalized increase in all amino acids but only in glutamate (sometimes a small amount of aspartate was seen); moreover, when the total increase in ninhydrin-reacting substances was measured this was approximately equal to the glutamate formed as measured by the Clostridium welchii decarboxylase. It therefore appears unlikely that the endogenous glutamic acid arises from the breakdown of protein.

Succinate. The sum of malate plus fumarate, $\alpha$ oxoglutarate and glutamate accounted for only about $50-60 \%$ of the citrate disappearing from the incubation medium. Incubation of a rat-liver cyclophorase preparation with ${ }^{14} \mathrm{C}$-labelled citrate and subsequent paper-chromatographic separation of the organic acids showed that about $40 \%$ of the counts disappearing from citrate appeared in an acid which cochromatographed with succinate. Subsequent analysis of further liver preparations incubated with non-isotopic citrate showed that succinate was a consistent product of the reaction.

Other products. On incubation in the absence of citrate the endogenous carbohydrate decreased and there was an increase in endogenous lactate. Incubation with citrate produced an increase in carbohydrate but greatly stimulated lactate production. For example, in a typical experiment incubation without substrate produced an increase in lactate of $0.44 \mu \mathrm{mole}$, whereas in the presence of citrate the increase was $1.7 \mu$ moles. In the case where the determination was made there was a small increase in $\beta$-hydroxybutyric acid on adding citrate.

If reaction (1) is to continue acetyl-coenzyme $A$ must be hydrolysed and acetate would be expected to accumulate. Tests showed that acetate did accumulate in amounts about 1.5 times that of the malate plus fumarate that was found. These findings imply the presence in the liver of deacylases active in hydrolysing acetyl-coenzyme $\mathrm{A}$.

Recovery of citrate disappearing as other products. It was not technically feasible to estimate all the possible products of anaerobic citrate metabolism in a single experiment. Therefore the results of many experiments have been combined and the yield of each compound has been expressed as the average percentage of the citrate disappearing in each individual experiment (Table 7). It appears probable from these results that most of the citrate disappearing anaerobically $(80 \%)$ has been

Table 7. Products of the anaerobic metabolism of citrate

The average percentage (on a molar basis) of citrate consumed that appeared in the products given below is shown. Other compounds include lactate, $\beta$-hydroxybutyrate and carbohydrate.

$$
\text { Compound }
$$

Malate

$\alpha$-Keto acids

Glutamic acid + glutamine

Succinate

Other compounds

$\begin{array}{cc}\begin{array}{c}\text { Percentage } \\ \text { of citrate }\end{array} & \begin{array}{c}\text { No. of } \\ \text { experiments }\end{array} \\ 10 & 7 \\ 4 & 9 \\ 32 & 11 \\ 34 & 6 \\ 19 & 8\end{array}$


accounted for as the sum of malate plus fumarate, keto acids, glutamic acid plus glutamine and succinate. The remaining $20 \%$ is apparently accounted for by carbohydrate, lactate and $\beta$ hydroxybutyrate. However, the number of estimations done on these three substances are not sufficient to be certain of the recovery, particularly as the percentage is heavily weighted by the contribution of carbohydrate, the formation of which varied greatly.

\section{DISCUSSION}

The rate of oxygen uptake by washed particulate preparations of liver in the presence of citrate or isocitrate is only about one-half of the rate that occurs with other members of the tricarboxylic acid cycle with the exception of malate. In unfractionated homogenates of rat liver citrate is oxidized at about $80 \%$ of the rate of the other acids, with the exception of malate or fumarate which are oxidized at a rate that is only some $50-60 \%$ of that of the other components (L. V. Eggleston unpublished work). The lowered rate of respiration in the presence of citrate on fractionation of the homogenate is probably due to the removal of the soluble isocitric dehydrogenase. It is generally agreed that the slow rate of oxidation of malate is due to the accumulation of oxaloacetate.

Under anaerobic conditions the occurrence of the following reactions is visualized:

$$
\begin{aligned}
& \begin{array}{l}
\text { Citrate + coenzyme } \mathrm{A} \leftrightharpoons \text { oxaloacetate }+ \\
\text { acetyl-coenzyme } \mathrm{A}
\end{array} \\
& \text { Acetyl-coenzyme } \mathrm{A} \rightarrow \text { acetate + coenzyme } \mathrm{A} \\
& \text { Oxaloacetate }+2 \mathrm{H} \leftrightharpoons \text { malate } \leftrightharpoons \text { fumarate } \\
& \text { isoCitrate }-2 \mathrm{H} \rightarrow \alpha \text {-oxoglutarate }+\mathrm{CO}_{2} \\
& \alpha \text {-Oxoglutarate }-2 \mathrm{H} \rightarrow \text { succinate }+\mathrm{CO}_{2} \\
& \alpha \text {-Oxoglutarate }+2 \mathrm{H}+\mathrm{NH}_{3} \leftrightharpoons \text { glutamate } \\
& \text { Oxaloacetate } \rightarrow \text { pyruvate }+\mathrm{CO}_{2} \\
& \text { Pyruvate }+2 \mathrm{H} \leftrightharpoons \text { lactate } \\
& \text { Fumarate }+2 \mathrm{H} \leftrightharpoons \text { succinate }
\end{aligned}
$$

The amount of oxaloacetate formed depends on the extent of reaction $(b)$. The reversal of $(b)$ requires the participation of ATP and under the anaerobic conditions of the experiments the level of ATP and other nucleotide triphosphates will be very low because of lack of oxidative phosphorylation and because the adenosine triphosphatase activity of the tissue preparations is high. The coupling of reactions $(c)$ and $(d)$ would lead to the formation of $\alpha$-oxoglutarate. Further coupling of $(d)$ and $(f)$ allows the accumulation of glutamate from isocitrate in the presence of only catalytic amounts of $\alpha$-oxoglutarate provided that a source of ammonia is available.
Source of ammonia and the formation of glutamic acid in the absence of substrate. It seems clear that the ammonia for the formation of glutamic acid from isocitrate does not arise by transamination from other amino acids since there was no corresponding increase in $\alpha$-keto acids in the medium. The total amount of glutamine available has not been measured but the endogenous content of glutamic acid plus glutamine was between only one-third and one-twentieth of the glutamic acid that was formed during incubation with citrate, and the glutamic acid plus glutamine that is liberated from endogenous sources on incubation in the absence of citrate is only one-half to oneseventh of the extra glutamic acid that is formed on incubation with citrate. Thus the apparent amounts of glutamine that are probably available fall considerably short of the amount of amino nitrogen that would be required for the observed formation of glutamate.

In most of the experiments ATP was added to the incubation medium. The possibility of this ATP acting as the ammonia donor was not directly tested but the following observations argue against it. The formation of glutamic acid was usually much greater than the $4 \mu$ moles of ATP added and glutamic acid was still formed when ATP was omitted from the incubation medium. Further, as judged by visual inspection of chromatograms that were run to separate the phosphate compounds of the incubated mixture, almost all of the added ATP was recovered as adenosine monophosphate. The formation of glutamate anaerobically from $\alpha$-oxoglutarate in homogenates has been described by Krebs et al. (1948), who also described the stimulating effect of citrate on this reaction. This paper extends these observations and shows that glutamic acid formation can occur in washed particulate preparations without the addition of ammonia and that substantial quantities of glutamic acid can be formed from endogenous sources.

Effect of coenzymes. The addition of DPN, TPN and ATP all increased the output of carbon dioxide from the preparations, as might be expected if they stimulated the isocitric enzyme (TPN), $\alpha$-oxoglutarate oxidase (DPN + ATP) and glutamic dehydrogenase (DPN or TPN).

Effect of ketone-binding substances. It would be expected that ketone-binding substances would inhibit the decarboxylation reactions involved by stabilizing the keto group adjacent to the carboxyl group undergoing decarboxylation. It was not expected that cyanide would completely inhibit citrate removal. This is probably because oxaloacetic cyanhydrin forms sufficiently fast to prevent any appreciable accumulation of oxaloacetate and $\alpha$-oxoglutarate and thus these compounds are not available to accept the hydrogen from isocitrate. 
Effect of ethylenediaminetetra-acetic acid. This probably functions by chelating the $\mathrm{Mn}^{2+}$ ions necessary for the isocitric enzyme (see Moyle \& Dixon, 1956).

Little attention appears to have been paid to the anaerobic metabolism of the citric acid cycle intermediates by mitochondrial and other washed particulate preparations. It is perhaps surprising to find such a high consumption of tricarboxylic acid under strictly anaerobic conditions by these preparations since the mitochondria are the sole site of the terminal oxidase of the electron-transport chain. The extensive oxidoreductions that can occur under anaerobic conditions emphasizes the danger of assessing substrate removal by simple measurement of the respiration in its presence since there seems no reason to expect that the competition of the DPN oxidase for the reduced coenzymes would remove them all from interaction with other enzymes and substrates.

\section{SUMMARY}

1. Washed particles of rat liver consumed citrate anaerobically at about $50 \%$ of the rate occurring aerobically.

2. The products of the anaerobic reaction were on the average malate plus fumarate $10 \%, \alpha$ oxoglutarate $4 \%$, glutamate $32 \%$ and succinate $34 \%$. Other substances found were carbohydrate, lactate and $\beta$-hydroxybutyrate.

3. The proportions of the substances formed anaerobically from citrate varied with the amount of tissue added and concentration of di- and triphosphopyridine nucleotide and adenosine triphosphate. These three substances increased the citrate consumption whereas dithionite, hydroxylamine and ethylenediaminetetra-acetic acid decreased it and cyanide completely abolished it.

4. Glutamic acid was formed from the tissue preparations on incubation without substrate and was also formed from the citrate added as substrate.
5. The anaerobic reactions of citrate are discussed.

We wish to thank Professor Sir Hans Krebs, F.R.S., for his interest and advice, and Mr L. V. Eggleston for supplying details of his unpublished work. The work was aided by a grant from the Rockefeller Foundation.

\section{REFERENCES}

Barker, S. B. \& Summerson, W. H. (1941). J. biol. Chem. 138, 535.

Calvin, M. \& Benson, A. A. (1949). Science, 109, 140.

El Hawary, M.F.S. \& Thompson, R.H.S. (1953). Biochem.J. 53, 340.

Friedemann, T. E. \& Haugen, G. E. (1943). J. biol. Chem. $147,415$.

Green, D. E., Loomis, W. F. \& Auerbach, V. H. (1948). J. biol. Chem. 172, 389.

Greenberg, L. A. \& Lester, D. (1944). J. biol. Chem. 154, 177.

Hummel, J. P. (1949). J. biol. Chem. 180, 1225.

Kornberg, H. L. (1958). Biochem. J. 68, 535.

Krebs, H. A. (1937). Biochem. J. 31, 2095.

Krebs, H. A. \& Eggleston, L. V. (1944). Biochem. J. 38, 426.

Krebs, H. A., Eggleston, L. V.\& Hems, R. (1948). Biochem. J. 43, 406.

Madsen, N. B. (1958). Biochim. biophys. Acta, 20, 85.

Massey, V. (1952). Biochem. J. 51, 490.

Miller, B. F. \& Van Slyke, D. D. (1936). J. biol. Chem. 114, 583.

Morrison, J. F. (1954). Biochem. J. 56, 99.

Moyle, J. \& Dixon, M. (1956). Biochem. J. 63, 548.

Nossal, P. M. (1951). Biochem. J. 49, 407.

Ochoa, S. (1948). J. biol. Chem. 174, 233.

Rosen, H. (1957). Arch. Biochem. Biophys. 67, 10.

Saz, H. J. \& Hillary, E. P. (1956). Biochem. J. 62, 563.

Serlin, J. \& Cotzias, G. (1955). J. biol. Chem. 215, 263.

Stern, J. R., Shapiro, B., Stadtman, E. R. \& Ochoa, S. (1951). J. biol. Chem. 193, 703.

Taylor, T. G. (1953). Biochem. J. 54, 48.

Vignais, P., Vignais, P. \& Bartley, W. (1957). Biochem. J. 65, 396.

Werkheiser, W. C. \& Bartley, W. (1957). Biochem. J. 66, 79.

\title{
The Identity of Natural and Synthetic $\beta \beta$-Dimethylacrylylcholine
}

\author{
By V. P. WHITTAKER \\ A.R.C. Institute of Animal Physiology, Babraham, Cambridge
}

(Received 7 July 1958)

The hypobranchial gland of the marine snail Thais floridana (Southern oyster drill) has recently been found to contain in relatively high concentration a biologically active ester, identified as $\beta \beta$. dimethylacrylylcholine (Whittaker, 1957; Keyl, Michaelson \& Whittaker, 1957). This paper describes the isolation of the naturally occurring ester as the chemically pure aurichloride, and presents additional evidence for the identity of the natural and synthetic compounds.

The aurichloride of the naturally occurring ester has almost the same melting point and gold content as the synthetic aurichloride and showed no depression of melting point when mixed with the 